\title{
Academic Procrastination of Undergraduate Students: The Role of Academic Self- efficacy and The Big Five Personality Traits
}

\author{
Yogi Swaraswati ${ }^{\mathrm{a}}$, A. Rachmad Djati Winarno ${ }^{\mathrm{b}}$, Haryo Goeritno ${ }^{\mathrm{c}}$ \\ Department of Psychology \\ Universitas Negeri Semarang \\ Semarang, Indonesia \\ e-mail: yogi.swaraswati@mail.unnes.ac.id \\ Faculty of Psychology \\ Universitas Katolik Soegijapranata \\ Semarang, Indonesia \\ e-mail: rdwinarno@unika.ac.id \\ Faculty of Psychology \\ Universitas Katolik Soegijapranata \\ Semarang, Indonesia \\ e-mail: haryo@unika.ac.id
}

\begin{abstract}
The current study aimed to examine the relationships between academic self-efficacy, the Big Five personality traits (extraversion, agreeableness, conscientiousness, neuroticism, and openness), and academic procrastination among undergraduate students. Two hundred and seven undergraduate students in Semarang participated in this study. A hundred and four were sophomores and 103 were third-year students. The results showed that academic self-efficacy and the Big Five personality traits predicted academic procrastination significantly $(R=0.815, F=65.874, p<0.01)$. Correlation analysis revealed that academic self-efficacy, extraversion, conscientiousness and neuroticism emerged as the predictors of the academic procrastination tendencies among undergraduate students. Neuroticism and extraversion had a positive significant relationship, while conscientiousness and academic self-efficacy had a negative significant association. Furthermore, the hypotheses about relationships between other personality traits (agreeableness and openness) with academic procrastination were not supported. Agreeableness and openness were not related to academic procrastination. Implications of academic self-efficacy and Big Five personality traits measures to the predictions of academic procrastination among undergraduate students are discussed.
\end{abstract}

Keywords—academic procrastination, academic self-efficacy, big five, personality traits

\section{INTRODUCTION}

Academic procrastination is a common problem that appears in the academic setting, where individual tend to putt of accomplishing academic assignments or activities toward the deadlines. It might occur among students in all educational degree, from elementary school to college [1]. However, most procrastination problems are found in colleges, especially among students [1]-[3]. Previous research has revealed that more than $70 \%$ of students perform procrastination regularly [4].

According to several researchers, academic procrastination is defined as an act of delaying the tasks irrationally and must be unnecessary by choosing other activities that are more interesting rather than dwelling on the tasks [3][5][6]. The students showed a task aversiveness, so they can not finish academic activities as planned [3][7]. The academic activities refer to learning habituation regularly based on curriculum such as exams, assignments, homeworks, presentation and practicums [8].

The academic responsibilities that must be completed by the deadline, requires the students have skilled in regulating the time, prioritizing and choosing appropriate learning strategies [9]. Moreover, they must be persistent to face difficulties while accomplishing certain academic tasks and activities as efforts to achieve academic success [10]. But in fact, academic achievement is not necessarily as expected. The students' problems in completing academic tasks set off academic procrastination propensities.

Sometimes students have external disruptions, relating to under pressure and deadline situations of academic or non-academic assignments [11] [12]. In addition, numerous studies focusing on academic procrastination have also revealed that low selfefficacy, low anxiety, low conscientiousness, perfectionism, and neuroticism as the antecedents of procrastination [3][8][13]. These conditions allow students to avoid the assignments. Thus, the problems might not only influenced by external factors, but also involves personal factors, such as the cognitive, emotional, and personality aspects of individual $[3][13][14]$.

The previous studies have proven that procrastination certainly impacts on detrimental academic performance (e.g., poor quality paper, poor grades) $[1][3][15][16]$, and length of the study period in college [17]. These potential implications of procrastination behavior on academic performance may indicate barriers that lead to other academic problems including individual internal conflicts. 
Among other factors, both self-efficacy and personality traits have established to be prominent predictors of academic procrastination [3][13]. Therefore, this present study attempted to explore the antecedents factor of academic procrastination on undergraduate students by examining its relations personal characteristics, such as academic self-efficacy and personality traits. Academic self-efficacy is defined as students' beliefs about their capability to implement a certain academic task that would reach an expected outcome [18]. In this case, the capability does not emphasize the level of individual competence, but rather to point out belief regarding the tasks and academic activities that can be done by students [19]. That is, academic self-efficacy would determine the individual's decision to complete or avoid the tasks.

A meta-analysis of 104 articles published with student populations showed a negative correlation between self-efficacy and procrastination $(r=-0.40)$ [13]. That is, low self-efficacy describes a high level of procrastination. In line with [13], another meta-analysis also confirmed that self-efficacy is a very robust and consistent predictor of procrastination [3] However, a different study has found the opposite condition, that is, there was a weak relationship between academic selfefficacy and academic procrastination [20].

Other findings showed the dynamics of correlation between academic self-efficacy and academic procrastination, that is, high self-efficacy would decrease the level of academic procrastination if the internal factor (e.g., intrinsic motivation) is relatively high. This condition does not apply otherwise, which means that if intrinsic motivation is low, it does not necessarily give significant results [21].

Most procrastinators also tend to associate failure with the internal situations. It reflected through the deficiencies of their personality [22]. A stressful situation could be a heavy burden that leads to maladaptive perfectionism and neurotic tendencies $[8][22][23]$. The procrastinator often argues that he takes a lot of time to finish the task in order to complete the task perfectly. Surely this condition will deplete the energy both physically and psychologically, so causing fatigue and ultimately triggering procrastination behavior [3][23]. Various reasons are maintained by the students despite causing detrimental consequences. Thus, personality is an essential aspect of psychology in determining individual behavior because procrastination tendencies have been shown to be relatively stable in time and circumstances [3] [13].

The Big Five personality traits' model consisting extraversion, agreeableness, conscientiousness, neuroticism, and openness have related on academic performance and procrastination. Several previous findings indicated the high correlation between the Big Five personality traits and academic performance $[3][7][13][24]$. A meta-analysis confirmed that neuroticism and conscientiousness had a significant correlate to academic procrastination, while agreeableness, extraversion, and openness have results inconsistent [3]. Findings of prior studies showed the positive association between neuroticism and procrastination, meanwhile between conscientiousness had a negative relationship. Procrastinators who have a high neuroticism are described as individuals who experience high anxiety and tend to be judge themselves caused by procrastination [22]. As well as low conscientiousness is described as being unorganized, powerless, unreliable, lazy, indifferent, reckless, and hedonistic [25]. It makes sense that people who have low scores in conscientiousness will be more vulnerable to procrastination because symbolize procrastinator characteristics. Based on the results of these studies, conscientiousness has revealed as a robust predictor, whilst neuroticism, agreeableness, extraversion, and openness were presented various results, especially in predicting the level of academic procrastination.

Tracing the literature of previous studies on academic procrastination within the scope of college revelead that the majority of research participants were senior students who are preparing a thesis. So, it becomes important to conduct studies on students who are still burdened with academic tasks, that is sophomores and third-year students. Thus, the current study aimed to examine the relationships between academic self-efficacy, the Big Five personality traits (extraversion, agreeableness, conscientiousness, neuroticism, and openness), and academic procrastination among undergraduate students.

\section{METHOD}

\section{A. Participants}

Participants in this study consisted of 207 undergraduate students of a public university in the cities of Semarang, Central Java, Indonesia. A hundred and four were sophomores (40 male and 64 female, age 18 -20 years, $M=19.13, S D=0.534$ ) and 103 third-year students (45 male and 58 female, age 19-21 years, $M=20.52, S D=0.654)$.

\section{B. Measures}

Academic procrastination was measured using a 32-item scale developed from Academic Procrastination Scale by McCloskey [1]. Participants rated their behavior on each item a 5-point Likert scale, ranging from 1 (never) to 5 (always) for a favorable item, while for an unfavorable item have a reverse range of scores. Sample items are, "I put off assignments until the last minute" (favorable item) and "I focus on the task completion, even though a lot of distractions" (unfavorable item). The corrected itemtotal correlation scores ranged from 0.324 to 0.689 ( $p<$ 0.01 ) and the Cronbach's alpha reliability was 0.916 .

Academic self-efficacy questionnaire was used to measure students' beliefs about their own capabilities to implement academic demands, such as individual and group assignments, midterms, final exams, and thesis on a certain level. It consists of 24-item scale according to three dimensions of self-efficacy from 
Bandura [18], i.e. magnitude, generality, and strength. Participants were asked to rate their agreement on a 5point Likert scale, ranging from "strongly disagree" (1) to "strongly agree" (5) for a favorable item, while for an unfavorable item have a reverse range of scores. Sample items are, "I believe to finish my academic assignments by deadlines" (favorable item) and "I confuse how to schedule my time to complete my tasks" (unfavorable item). For the current study, corrected item-total correlation scores ranged from 0.427 to $0.652(p<0.01)$. The Cronbach's alpha reliability was 0.91 .

The Big Five personality traits were assessed using a 44-items of The Big Five Inventory (The BFI) developed by John \& Srivastava (1999). It assesses five personality traits domains, such as extraversion (8 items), agreeableness ( 9 items), conscientiousness (9 items), neuroticism (8 items), and openness (10 items). Participants rated the item on a 5-point Likert type scale, ranging from 1 (strongly disagree) to 5 (strongly agree). Sample items are, "I see myself as someone who generates a lot of enthusiasm (extraversion); has a forgiving nature (agreeableness); is a reliable worker (conscientiousness); can be tense (neuroticism); is curious about many different things (openness)." The BFI was translated and adapted into Indonesian language utilizing ABBA (forward-back translation) technique by Sulastri (2014). The Cronbach's alpha reliability was 0.75 for extraversion, 0.65 for agreeableness, 0.73 for conscientiousness, 0.80 for neuroticism, and 0.66 for openness.

High scores on the measures indicated high academic procrastination, academic self-efficacy, extraversion, agreeableness, conscientiousness, neuroticism, and openness.

\section{Procedure}

Participants were asked to complete three instruments, i.e. academic procrastination questionnaire, academic self-efficacy questionnaire, and The Big Five Inventory. Instructions about how it should be completed were presented at the top of each questionnaires. Completed questionnaire were returned to the researchers.

\section{Data Analysis}

The data were analyzed using three statistical technique, i.e., descriptive statistics analysis, the multiple linear regression analysis to estimate a predictors' role to criterium variable simultaneously and Pearson product moment correlations to reveal a correlation of each predictor variable with academic procrastination tendencies among undergraduate students.

\section{RESULTS AND DISCUSSION}

\section{A. Results}

The results are presented in three parts. First, we describe means, standard deviations, and collinearity statistics using descriptive statistics analysis (see Table
I). Moreover, we also present categorization of academic procrastination (see Table II). Second, we used multiple regression analysis to determine the best linear combination of academic self-efficacy and the Big Five personality traits (extraversion, agreeableness, conscientiousness, neuroticism, and openness) and which predictors have a significant influence on academic procrastination among undergraduate students simultaneously. Finally, we analyzed using Pearson product moment correlation to estimate whether each predictor variables, i.e., academic selfefficacy and the Big Five personality traits have a relationship with academic procrastination.

\section{1) Descriptive Statistics}

The means, standard deviations, and collinearity statistics of academic self-efficacy, and the Big Five Personality Traits $(N=207)$ can be found in Table I.

TABLE I. MEAns, StANDARD DEVIATIONS, AND COLLINEARITY STATISTICS

\begin{tabular}{|l|c|l|l|l|}
\hline \multirow{2}{*}{ Variable } & \multirow{2}{*}{$\boldsymbol{M}$} & \multirow{2}{*}{$\boldsymbol{S D}$} & \multicolumn{2}{c|}{$\begin{array}{c}\text { Collinearity } \\
\text { Statistics }\end{array}$} \\
\cline { 4 - 6 } & & & Tolerance & VIF \\
\hline $\begin{array}{l}\text { Academic } \\
\text { Procrastination }\end{array}$ & 95.71 & 12.037 & - & - \\
\hline $\begin{array}{l}\text { Academic Self- } \\
\text { efficacy }\end{array}$ & 79.47 & 9.582 & 0.872 & 1.147 \\
\hline Extraversion & 23.11 & 4.960 & 0.800 & 1.251 \\
\hline Agreeableness & 33.19 & 4.184 & 0.994 & 1.006 \\
\hline Conscientiousness & 24.49 & 5.695 & 0.837 & 1.195 \\
\hline Neuroticism & 23.97 & 4.961 & 0.835 & 1.198 \\
\hline Openness & 95.71 & 12.037 & 0.826 & 1.211 \\
\hline
\end{tabular}

As presented in Table I, all tolerances of predictor variables consisting of academic self-efficacy, extraversion, agreeableness, conscientiousness, neuroticism, and openness are well over $0.336\left(1-\mathrm{R}^{2}\right)$. Thus, the results did not indicate multicollinearity. Hereafter, hypotheses testing can proceed.

\section{TABLE II. CATEGORIZATION OF ACADEMIC} PROCRASTINATION

\begin{tabular}{|l|l|l|l|}
\hline Range Score & \multicolumn{1}{|c|}{$\boldsymbol{c}$} & \multicolumn{1}{c|}{$\begin{array}{c}\text { Percentage } \\
(\%)\end{array}$} & \multicolumn{1}{c|}{ Category } \\
\hline $\mathrm{X} \leq 64$ & 2 & 0.97 & Very low \\
\hline $64<\mathrm{X} \leq 85$ & 45 & 21.74 & Low \\
\hline $85<\mathrm{X} \leq 107$ & 129 & 62.32 & Moderate \\
\hline $\begin{array}{l}107<\mathrm{X} \leq \\
128\end{array}$ & 31 & 14.98 & High \\
\hline $\mathrm{X}>128$ & 0 & 0 & Very high \\
\hline
\end{tabular}

Description of the data in Table II provides an overview of scores distribution of academic procrastination. It is useful as an information source about the participants' conditions. Based on Table II, it can be seen that academic procrastination of the undergraduate students was mostly at the moderate 
level $(N=129,62.32 \%)$. Furthermore, forty-four participants $(24.74 \%)$ had a low level of academic procrastination, $0.97 \%(N=2)$ participants had a very low level, and $14.98 \%(N=31)$ participants had a high level of academic procrastination. Meanwhile, there were no participants included in the very high academic procrastination category.

\section{2) Results of Hypotheses Testing}

The results of hypotheses testing consisted of two sections, i.e., the major hypothesis and minor hypotheses testing. The multiple regression analysis was conducted to examine major hypothesis, whether academic self-efficacy and the Big Five personality traits (extraversion, agreeableness, conscientiousness, neuroticism, and openness) predicted academic procrastination simultaneously (see Table III for results).

TABLE III. SUMMARY OF MULTIPLE REGRESSION ANALYSIS BETWEEN THE PREDICTOR VARIABLES AND ACADEMIC PROCRASTINATION

\begin{tabular}{|c|c|c|c|c|c|}
\hline $\begin{array}{c}\text { Mode } \\
\mathbf{l}\end{array}$ & $\boldsymbol{R}$ & $\boldsymbol{R}^{2}$ & $\begin{array}{c}\text { Adjuste } \\
\mathbf{d ~ R}^{2}\end{array}$ & $\begin{array}{c}\text { Std. Error } \\
\text { of the } \\
\text { Estimatio } \\
\mathbf{n}\end{array}$ & $\boldsymbol{F}$ \\
\hline 1 & $\begin{array}{l}0.815 \\
\mathrm{a}\end{array}$ & $\begin{array}{l}0.66 \\
4\end{array}$ & 0.654 & 7.081 & $\begin{array}{l}65.874 \\
\mathrm{~b}\end{array}$ \\
\hline
\end{tabular}

a.Predictors: Academic Self-efficacy, Extraversion, Agreeableness, Conscientiousness, Neuroticism, Opennes

${ }^{\mathrm{b}}$ Dependent Variable: Academic Procrastination c. $p<0.01$

From Table III, results showed that the multiple correlation coefficient $(R)$, using all the predictors simultaneously, was $0.815\left(R^{2}=0.664\right)$ and the adjusted $R^{2}$ was 0.654 . It appeared that when all predictor variables were combined, $65.4 \%$ of the variance in academic procrastination can be predicted from academic self-efficacy and the Big Five personality traits. Table III also shows that $F=49.434$ $(p<0.01)$. This indicates the combination of academic self-efficacy and the Big Five personality traits significantly predict academic procrastination.

TABLE IV. PEARSON'S CORRELATIONS OF ACADEMIC SELF-EFFICACY, BIG FIVE, AND ACADEMIC PROCRASTINATION

\begin{tabular}{|l|l|l|}
\hline \multicolumn{1}{|c|}{ Variable } & \multicolumn{1}{c|}{$\begin{array}{c}\text { Academic } \\
\text { Procrastination }\end{array}$} & \multicolumn{1}{c|}{$\boldsymbol{p}$} \\
\hline $\begin{array}{l}\text { Academic Self- } \\
\text { efficacy }\end{array}$ & $-0.532^{* *}$ & 0,000 \\
\hline Extraversion & $0.207 * *$ & 0.003 \\
\hline Agreeableness & 0.079 & 0.255 \\
\hline Conscientiousness & $-0.677^{* *}$ & 0.000 \\
\hline Neuroticism & $0.533^{* *}$ & 0.000 \\
\hline Openness & -0.026 & 0.706 \\
\hline & & ${ }^{\mathrm{a} \cdot} N=207$ \\
b.*** $p<0.01^{2}$
\end{tabular}

Correlation analysis showed that academic selfefficacy, extraversion, conscientiousness, and neuroticism emerged as the predictors of the academic procrastination among undergraduate students (see Table IV). neuroticism $(r=0.533, p<0.01)$ and extraversion $(r=0.207, p<0.01)$ had a positive significant relationship, while conscientiousness $(r=-$ $0.677, p<0.01)$ and academic self-efficacy $(r=-0.532$, $p<0.01)$ had a negative significant association. Conscientiousness revealed to have the highest correlation with academic procrastination. Furthermore, relationships between other personality traits (agreeableness and openness) and academic procrastination were not supported. agreeableness $(r=$ $0.079, p>0.05)$ and openness $(r=-0.026 p>0.05)$ were not related to academic procrastination.

\section{B. Discussion}

Results of the current study provide strong espouse to previous studies investigating correlations between academic procrastination, academic self-efficacy, and the Big Five personality traits [3][13]. When all predictor variables were examined simultaneously conducting a multiple regression analysis, the result showed that academic self-efficacy and the Big Five personality traits predicted academic procrastination significantly. This finding suggests that academic selfefficacy and the Big Five personality traits are a strong internal antecedent of academic procrastination. However, if each predictor variable investigated separately, the findings found that not all predictor variables were related to academic procrastination.

The negative correlation between academic selfefficacy and academic procrastination was consistent with previous studies [3][13][19][20]. The results of two meta-analyses revealed that self-efficacy is a strong predictor of academic procrastination [3][13]. These studies suggest that low self-efficacy is the main reason for procrastination [3][20]. Low self-efficacy and high procrastination have strong associations with fear of failure, but regardless of this factor, self-efficacy has a direct connection to procrastination and performance [3].

Corresponding to the results, it was not surprising that students with high self-efficacy have a high intrinsic motivation and would be more likely to keep a persistent effort to accomplish the tasks [10][20]. Conversely, the students with low self-efficacy would be unfocused on their academic goals, lack of initiative, dependent on others or group, and tend to do procrastination [1] [9] [19]. If a student lacks initiative, he or she was inclined to rely on external motivation (e.g., reward) and lack a certain drive for accomplishing assignments on time [1]. Moreover, low self-efficacy also triggered academic procrastination caused by hesitation to take an initiative for starting to do the tasks [26]. Thus, academic self-efficacy was determined by students' decision, whether they would be fight or flight for finishing their tasks, such as individual assignments, group assignments, midterms, and final exams. 
The next findings are suggested contributions of the Big Five personality traits to academic procrastination among undergraduate students. As the prior studies indicate, it is clear that personality traits are an important antecedent affecting procrastination, including academic procrastination [3] [13] [26]-[28]. In regards to personality traits and academic procrastination, the findings of this study depicted that extraversion, conscientiousness, and neuroticism were related to academic procrastination. While agreeableness and openness were not associated.

In line with previous research, extraversion was positively correlated with procrastination [23]. Extraversion refers to individuals' general propensity to engage in social situations [25] [29]. Students who have high scores in this trait might procrastinate because they have a lot of disruptions in completing the academic assignments. The extraverts are more oriented to social aspects (e.g., making friends and looking for fun situations), so that they tend to require more stimulation from a warm social environment and provide comfort rather than dwell on academic tasks [23]. Consequently, they are inclined difficult to start and complete a task on time. We found support for previous study confirming that a common distraction and social activities with friends as the antecedents of procrastination [6].

Unexpected findings are shown by the relationship between agreeableness and academic procrastination among undergraduate students. The result was contradicted by meta-analysis findings that explaining a negative relationship between agreeableness and procrastination [3]. It appeared that results of the prior study regarding the non-significant association between the both variables resembling this finding [30]. Inconsistent results might occur due to a weak correlation between agreeableness and academic procrastination [3]. Nevertheless, the logical interpretation could elaborate on these results' inconsistency. Conceptually, agreeableness reflects what people do with each other and to each other [29]. The characteristics consist of soft-hearted, good, helpful, natures, trusting, forgiving, tender-minded and straightforward [29]. It means that agreeableness reflects interpersonal style rather than behavior processes so that it might be fundamentally irrelevant to the process of procrastination. Thus, it can be described that an agreeable or disagreeable student also procrastinate academic assignments potentially.

Furthermore, conscientiousness showed a negative significant correlation to academic procrastination. Academic procrastination thus increases as conscientiousness decreases. This result corroborated the prior studies confirming that conscientiousness emerged as the most robust predictor of academic procrastination [1][3][7][13][26][30]. It suggests that students with high conscientiousness are less likely to procrastinate as they are higher in qualities such as task-oriented, dependable, self-discipline, and achievement-oriented [25][29]. Meanwhile, low conscientiousness reflects inconsistent propensity, aimless, lazy, negligent, careless, weak-willed, and hedonistic [29]. Hence, procrastinators are identified as unorganized, low motivated, lazy and less achievement-oriented. It makes sense that people who have low score conscientiousness will be more vulnerable to be procrastinators.

Our study also revealed that neuroticism was positively and significantly associated with academic procrastination. It espouse past studies [3][26][27][30]. Findings of the current study suggest that student with neuroticism reflects worrying, nervous, emotional, insecure, inadequate and impulsive are more likely contribute to academic procrastination. As stated by previous researchers that people with high anxiety tend to judge and blaming themselves for their procrastination behavior, so susceptible to decreased performance and also more likely impulsive [22]. The higher of neuroticism level, the students are unable to focus on achieving the goal because of impulsive and anxious. While students who have low neuroticism tend to more stable and focus on accomplishing academic tasks.

Further, empirical data has shown the nonsignificant correlation between openness and academic procrastination. This finding is consistent with previous studies [3][26][27][30], which states that no correlation exists between openness and procrastination. The underlying reason is openness attributed to the talents, feelings, challenges, imagination, and intellectual curiosity, do not have the association with mood or academic qualities [3]. Based on theoretical perspective, openness is described as the breadth, depth, and complexity of individual mental and experiential life [29]. It means that openness is more related to the varying interests, intellectual and cultural domains of a person [31], so it is difficult to find the linearity between openness and academic procrastination.

This study had several limitations. The present study is limited to the role of internal antecedents, that is academic self-efficacy in general and the Big Five personality traits. Therefore, the further research needs to consider the role of the external factors, such as the task characteristics, clarity of assignment instructions from lecturers and students' involvement in organizations. The further analysis needs to be done, for example by controlling sex, performing comparisons between the grade and also using larger numbers of samples. Hereafter, it would be fascinating to get students from the various population (e.g. students of the junior high school, senior high school, vocational high school, boarding school, etc) and different courses area to complete the same test and see how the Big Five personality traits describe an actual academic performance.

It aims to enrich information on the problems of academic procrastination and its expectations can be found ideal patterns of intervention to solve the problem comprehensively. The results of this study have proven the importance of personality traits, especially conscientiousness and neuroticism as well as academic self-eficcacy in predicting academic 
procrastination of undergraduate students. Therefore, the educators provide educational services to students and minimize the barriers that have a negative effect on the learning process. Lecturers are expected to optimize the mentoring program related to academic orientation and career overview to the future, since the beginning of the first-year lecture, so that information can be the foundation for junior students to design their career.

\section{CONCLUSIONS}

Based on the results of hypotheses verification and discussion, it can be concluded that our research provides strong support for the role of academic selfefficacy and the big five personality traits in explaining academic procrastination tendencies among undergraduate students. We found that academic selfefficacy, extraversion, conscientiousness, and neuroticism are related to academic procrastination. Neuroticism and extraversion had a positive significant relationship, while conscientiousness and academic self-efficacy had a negative significant association. Furthermore, agreeableness and openness were not related to academic procrastination.

\section{ACKNOWLEDGMENT}

We would like to thank all those who participated in the study and helped to facilitate the research process. Especially for Mrs. Augustina Sulastri who has been willing to provide the adaptation and translation in Indonesian language version of the Big Five Inventory, so as to facilitate the implementation of this study.

\section{REFERENCES}

[1] J. D. McCloskey, "Finally, my thesis on academic procrastination," University of Texas, 2011.

[2] G. Schraw, T. Wadkins, and L. Olafson, "Doing the things we do: A grounded theory of academic procrastination.," J. Educ. Psychol., vol. 99, no. 1, pp. 12-25, 2007.

[3] P. Steel, "The nature of procrastination: A meta-analytic and theoretical review of quintessential self-regulatory failure.," Psychol. Bull., vol. 133, no. 1, pp. 65-94, 2007.

[4] G. Schraw, T. Wadkins, and L. Olafson, "Doing the things we do: A grounded theory of academic procrastination.," J. Educ. Psychol., vol. 99, no. 1, pp. 12-25, 2007.

[5] G. E. Prayitno, I. B. Siaputra, and H. K. Lasmono, "Validasi alat ukur Irrational Procrastination Scale ( IPS )," Calyptra, J. Ilm. Mhs. Univ. Surabaya, vol. 2, no. 1, pp. 1-7, 2013.

[6] K. T. Strongman and C. D. B. Burt, "Taking breaks from work: An exploratory inquiry," J. Psychol., vol. 134, pp. 229-242, 2000

[7] E. Adrianta and S. Tjundjing, "Mahasiswa Versus Tugas Prokrastinasi Akademik dan Conscientiousness .," Anima, Indones. Psychol. J., vol. 22, no. 4, pp. 352-374, 2007.

[8] M. Kağan, C. Osman, T. Ilham, and M. Kandemir, "The explanation of the academic procrastination behaviour of university students with perfectionism, obsessive Compulsive and five factor personality traits," Procedia - Soc. Behav. Sci., vol. 2, no. 2, pp. 2121-2125, 2010.

[9] S. S. Sansgiry, A. A. Kawatkar, A. P. Dutta, and M. J. Bhosle, "Predictors of academic performance at two universities: The effects of academic progression," Am. J. Pharm. Educ., vol. 68, no. 4, pp. 1-7, 2004.
[10] J. E. Ormrod, Educational psychology: Developing learners, 8th ed., Colorado: Pearson., 2014.

[11] J. R. Ferrari, "Procrastination as self-regulation failure of performance: Effects of cognitive load, self-awareness, and time limits on 'working best under pressure," Eur. J. Pers., vol. 15, no. 5, pp. 391-406, 2001.

[12] J. R. Ferrari, and S. J. Scher, “ Toward an understanding of academic and non-academic tasks procrastinated by students: The use of daily logs," Psychol. in. Sch., vol. 34, pp. 359-366, 2000

[13] W. van Eerde, "A meta-analytically derived nomological network of procrastination," Pers. Individ. Dif., vol. 35, no. 6 , pp. 1401-1418, 2003.C. Senécal, E. Julien, and F. Guay, "Role conflict and academic procrastination: A self-determination perspective," Eur. J. Soc. Psychol., vol. 33, pp. 135-145, 2003.

[14] L. A. Rabin, J. Fogel, and K. E. Nutter-Upham, “Academic procrastination in college students: The role of self-reported executive function," J. Clin. Exp. Neuropsychol., vol. 33, no. 3, pp. 344-357, 2011.

[15] L. M. Zarick and R. Stonebraker, "I'll do it tomorrow: The logic of procrastination," Coll. Teach., vol. 57, no. 4, pp. 211215, 2009.

[16] C. P. Joubert, "The relationship between procrastination and academic achievement of high school learners in North West province, South Africa," UNISA Institutional Repository, Tshwane, 2015.

[17] A. H. Muhammad and R. Hendriyani, "Perilaku prokrastinasi akademik mahasiswa Universitas Negeri Semarang," unpublished.

[18] A. Bandura, Self-efficacy: The exercise of control,. New York: W.H. freeman and Company., 1997.

[19] E. Pudjiastuti, "Hubungan self-efficacy dengan perilaku menyontek mahasiswa psikologi," Mimbar., vol. 28, pp. 103 $112,2012$.

[20] R. M. Klassen and E. Kuzucu, "Academic procrastination and motivation of adolescents in Turkey," Educ. Psychol., vol. 29, no. 1, pp. 69-81, 2009.

[21] I. Katz, K. Eilot, and N. Nevo, "'I'll do it later': Type of motivation, self-efficacy and homework procrastination," Motiv. Emot., vol. 38, no. 1, pp. 111-119, 2014.

[22] J. B. Burka and L. M. Yuen, Procrastination why you do it, what to do about it now, Revised Ed. Cambridge: Da Capo Press, 2008.

[23] J. R. Ferrari, J. L. Johnson, and W. G. McCown, Procrastination and task avoidance: Theory, research, and treatment. New York: Plenum Press., 1995.

[24] A. Furnham, S. Nuygards, and T. Chamorro-Premuzic, "Personality, assessment methods and academic performance," Instr. Sci., vol. 41, no. 5, pp. 975-987, 2013.

[25] J. Feist and G. J. Feist, Theories of personality, 7th ed., McGraw-Hill, 2009.

[26] H. Karatas, "Correlation among academic procrastination, personality traits, and academic achievement," Anthropologist, vol. 20, no. 1-2, pp. 243-255, 2015.

[27] S. Kim, S. Fernandez, and L. Terrier, "Procrastination, personality traits, and academic performance: When active and passive procrastination tell a different story," Pers. Individ. Dif., vol. 108, pp. 154-157, 2017.

[28] J. L. Johnson and A. M. Bloom, "An analysis of the contribution of the five factors of personality to variance in academic procrastination," Pers. Individ. Dif., vol. 18, no. 1, pp. 127-133, 1995.

[29] L. A. Pervin, D. Cervone, and O. P. John, Personality theory and research, New York: John Wiley and Sons, Inc, 2005.

[30] D. C. Watson, "Procrastination and the five-factor model: a facet level analysis," Pers. Individ. Dif., vol. 30, pp. 149-158, 2001.

[31] E. Mastuti, "Analisis faktor alat ukur kepribadian big five (adaptasi dari IPIP) pada mahasiswa suku Jawa," Insan., vol. 7 , no. 3, pp. 264-276, 2005. 